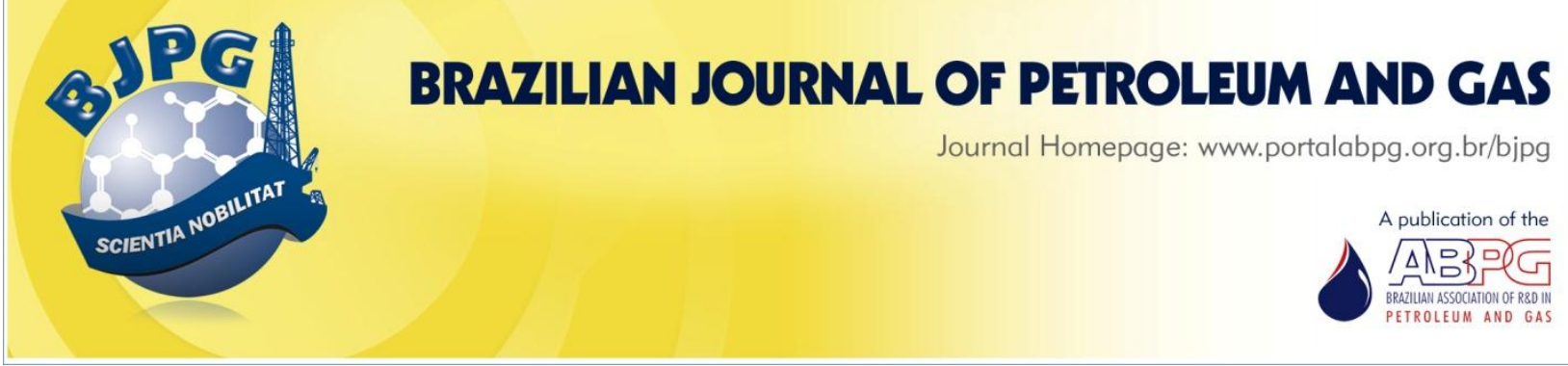

\title{
GENERAL GUIDELINES FOR DEVELOPING EXECUTIVE DESIGN OF NATURAL GAS URBAN PIPELINE NETWORKS AND USING HDPE VALVE
}

[This is a shortened version of the title: NATURAL GAS URBAN PIPELINE NETWORK DESIGN]

${ }^{\text {a }}$ Almeida, J. C. ${ }^{1}$; ${ }^{\text {a }}$ Macieski, G. C.; ${ }^{\text {a }}$ Zanette, L. A.

${ }^{\text {a }}$ Natural Gas Company of Paraná - COMPAGAS, Brazil

\section{ABSTRACT}

This paper's main objective is to describe the development of executive design methodology for urban natural gas pipeline networks, with a subdivided setup into "blocking areas", which are described as groups of urban blocks with independent supply interruption from the remainder system. In parallel, together with the implementation of a system with this setup, it presents a suggestion of using a specific model of valve chambers made of high density polyethylene- HDPE- for customer service branch connections, aiming to provide operational flexibility and low implementation costs to the distribution system. The case under study was developed at COMPAGAS, the natural gas company of Paraná, Brazil.

\section{KEYWORDS}

natural gas; pipeline network; HDPE; valve chamber; block areas

\footnotetext{
${ }^{1}$ To whom all correspondence should be addressed.

Address: Natural Gas Company of Paraná - COMPAGAS, Rua Hasdrúbal Bellegard, 1177 - Cidade Industrial, Curitiba, PR, Brazil Zip Code: 81460-120 | Phone number: (55) 41 3312-1924 | e-mail: j.cezar@compagas.com.br ; j.cezar@ufpr.br doi:10.5419/bjpg2015-0003
} 


\section{INTRODUCTION}

The growing market for natural gas in Brazil generates a demand for the expansion of distribution pipeline networks and, consequently, the need for continuous improvement of techniques and operational procedures. These procedure reviews aim to guarantee safety and continuity to the service, so the local distribution companies can maintain efficient and profitable operations while expanding their distribution pipeline networks. These strategies take into account that the increase in operational costs is related directly to the growth of this infrastructure.

Specifically in commercial and residential markets, this situation is even more critical. Those segments have similar design an operation features, mainly the large capillarization of pipeline networks in densely urbanized areas of big cities. In Brazil, according to ABEGAS (2014) most recent data, although the percentage of natural gas consumed daily by customers of these segments in November 2012 was about $1.4 \%$ of the total daily consumption, the total number of customers was $2,196,225$, representing $99.79 \%$ of the total number of customers. In the same period, Brazil's total distribution of pipeline networks extensions was $22,397.00$ kilometers, growing at an average rate of $10 \%$.

The present paper seeks to present an alternative solution for supplying residential and commercial clients in large urban centers. It highlights a setup model for distribution pipeline networks subdivided into perimeters henceforth designated as "blocking areas." It proposes the use of a valve chamber made of HDPE - high density polyethylene, specifically designed for the installation of blocking valves in customer service branches. This suggestion has as secondary objectives: to rationalize the spending of system investors, to ease network implementation and operation, to enable and facilitate its expansion, to ensure safety to system users; and, finally, to reduce costs by using custom designed HDPE chambers. These chambers were developed by the authors of this paper in partnership with a local plastic company.

The referred system was developed and implemented in the urban natural gas distribution network of COMPAGAS, a state owned natural gas company of Paraná, located in the city of Curitiba, Brazil.

\section{MATERIALS AND METHODS}

\subsection{The Urban Distribution System established by COMPAGAS}

The natural gas distribution system proposed consists of a set of pipes and further installations which, receiving gas from key delivery points, allow its distribution and delivery to final consumers. The main pipelines operate at $35 \mathrm{kgf} / \mathrm{cm}^{2}$ or $17 \mathrm{kgf} / \mathrm{cm}^{2}$ pressures, while secondary pipelines (side pipelines) operate at $7 \mathrm{kgf} / \mathrm{cm}^{2}$ or $4 \mathrm{kgf} / \mathrm{cm}^{2}$ pressures. Urban networks consist of side pipelines, which are planned according to the location of consumption points. The connections between pipelines that operate at different pressures are made with devices called Pressure Reducing Stations, "ERPs." These devices consist of a set of equipment and accessories designed to adjust differential pressures between upstream and downstream pipelines. This system was designed according requisites established by ASME B31.8 (ASME, 2007) and NBR 12.712 (ABNT, 2002) codes.

Figure 1 illustrates a schematic diagram of the natural gas distribution system proposed.

\subsection{The High Density Polyethylene (HDPE)}

The polyethylene has been used in pipe manufacturing for over 50 years in sectors of water distribution, sewer systems, and gas distribution (Frank et al., 2010). The first generation of polyethylene, the PE63 resin, was first commercialized in the ' 60 s, being used exclusively in water distribution and sewer systems. At end of the '70s, the PE80 resin was developed, whereas at end of the next decade the first PE100 resin pipe was produced, being considered the second and third generations of polyethylene (DHEUR et al., 2010). Recently, some countries, given sequence in development of HDPE, have created the fourth generation of PE, the PE100 RC (resistant to crack), which has a high resistance to stress cracking (Belloir \& Libert, 2010).

PE80 and PE100 are used commonly in the making of natural gas distribution networks. These pipes allow pressures up to $4 \mathrm{kgf} / \mathrm{cm}^{2}$ and 7 $\mathrm{kgf} / \mathrm{cm}^{2}$, respectively, fulfilling the requisites of standard NBR-14461 (ABNT, 2000). 


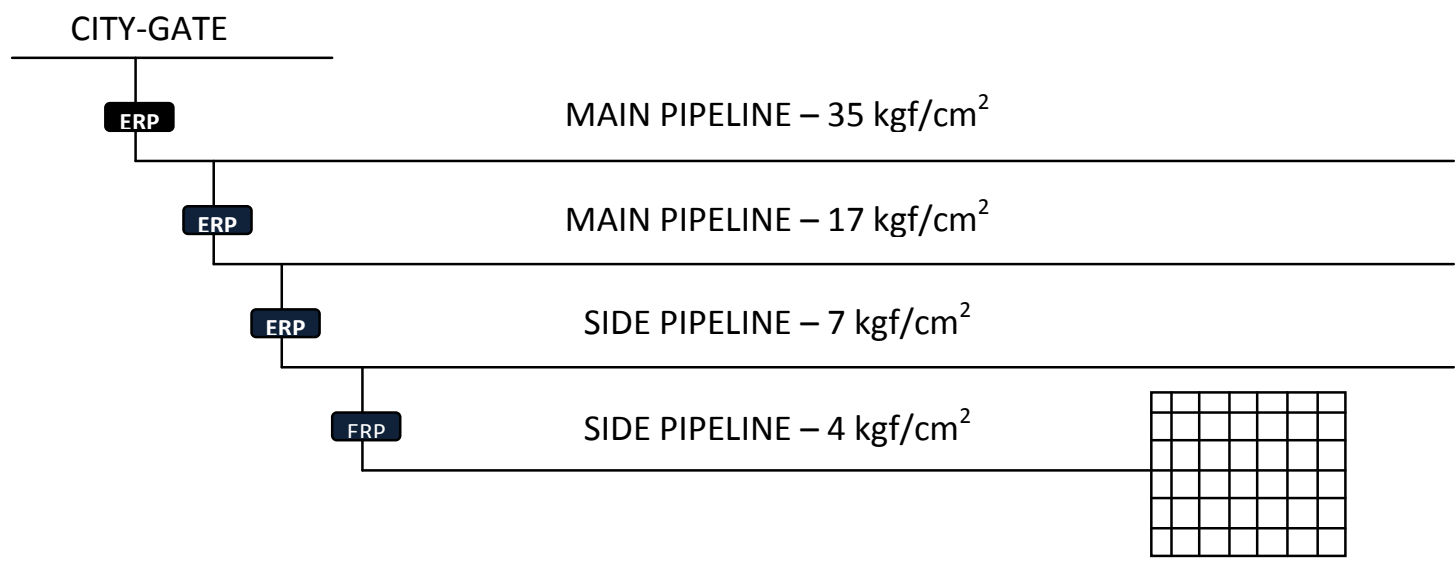

DISTRIBUTION NETWORK

Figure 1. Schematic of natural gas distribution pipeline network - COMPAGAS.

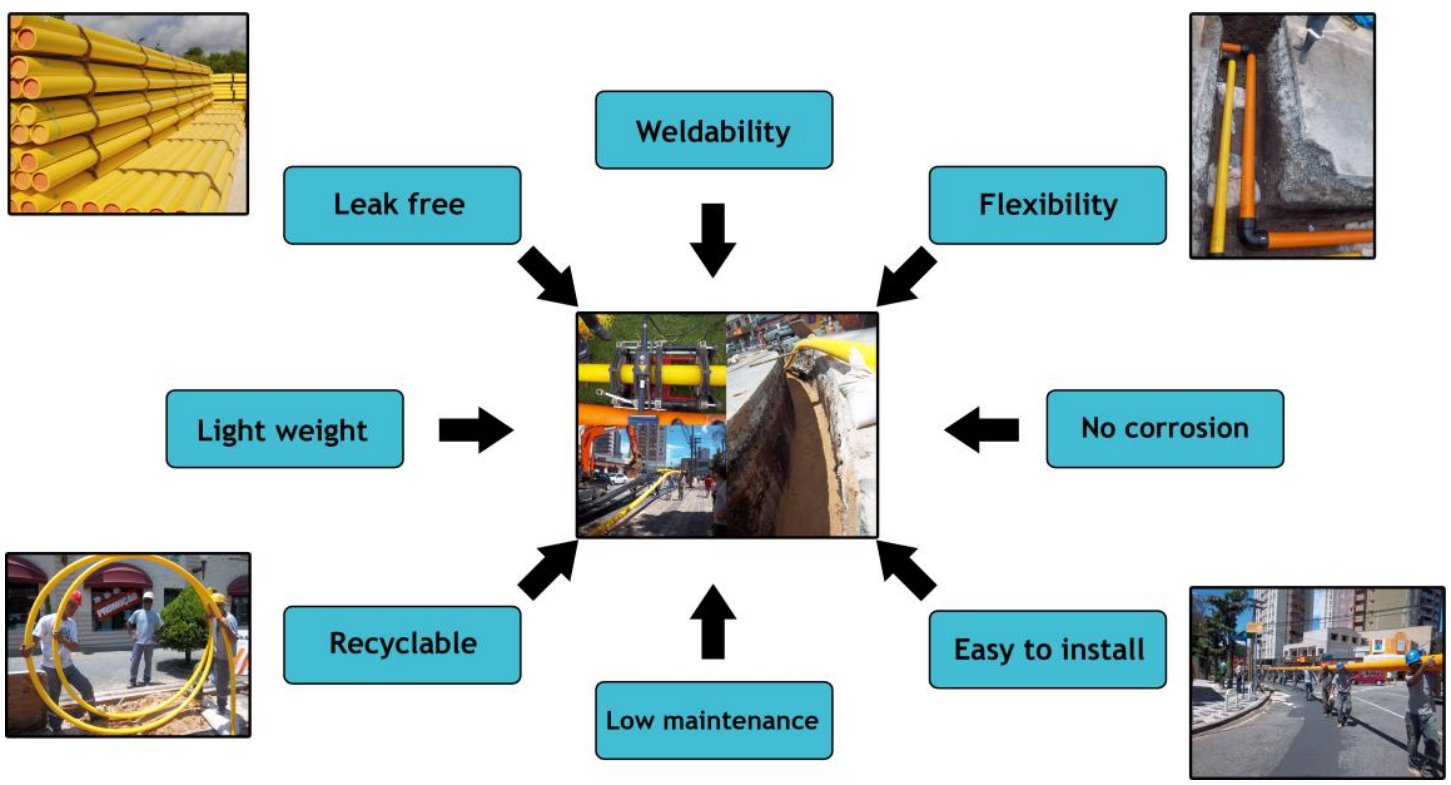

Figure 2. Main advantages of Polyethylene.

Source: Dheur et al., 2010 (adapted by the authors).

The demand for using polyethylene pipes in natural gas distribution, has grown significantly due to its advantages over carbon steel pipes, which often were used in the construction of gas distribution networks. Figure 2 illustrates some of these main advantages.

\subsection{Contextualization}

This paper's case study is very specific as it investigated the natural gas distribution pipeline network in the urban segment operated by COMPAGAS, the Paraná State natural gas company, located in the city of Curitiba, Brazil. The network mentioned consists of HDPE PE-80 OD $63 \mathrm{~mm}$ SDR
11 pipes, operating at $4.0 \mathrm{kgf} / \mathrm{cm}^{2}$ pressure. This network is subdivided in perimeters named "blocking areas," which consist of groups of city blocks interconnected by the above mentioned pipes. Each customer service branch comes from these perimeters, which are extended along sidewalks. These blocking areas are connected to an upstream pipe (side pipeline) at two different points with block valves. An example of this setup is illustrated in Figure 3.

The main approach for natural gas urban distribution networks involves the strategic study for the implementation of side pipelines at 4 $\mathrm{kgf} / \mathrm{cm}^{2}$ or $7 \mathrm{kgf} / \mathrm{cm}^{2}$ pressures, and the analysis of 


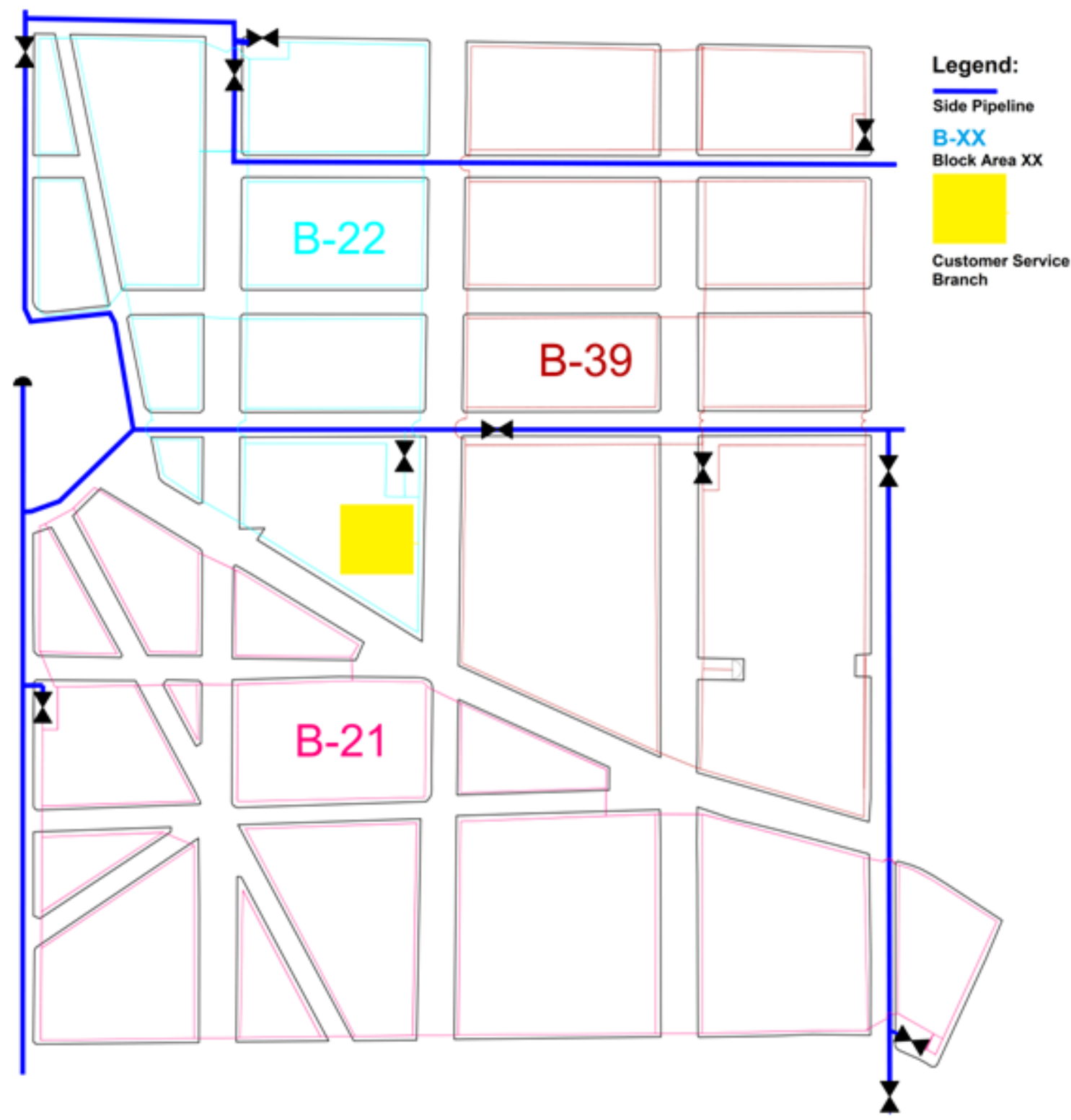

Figure 3. COMPAGAS' network set up with blocking areas.

the network's geography itself. It takes into account the location of consumption points, as side pipelines can also be used in the direct supply of gas to specific customers such as filling stations. These pipes usually are extensive and costly, justifying the development of strategies aiming to rationalize investor's spending.

The first step in network conception is the delimitation of the urban area to be supplied by the natural gas system- the establishment of the project area. This step considers the statistical data compiled by relevant public agencies. Among the data analyzed are the urban zoning criteria defined by city planning agencies, and the real data collected in the local area through technical visits, such as the identification of potential customers in high demand areas like shopping centers, hospitals, and filling stations.

\subsection{Mesh modulation}

The modulation of the urban mesh for gas supply aims to enable a controlled and fast maintenance, with minimum interference in the mesh during operations. This modulation is obtained by dividing the supplying area into smaller areas- "blocking areas." These areas are designed considering the following basic features: 


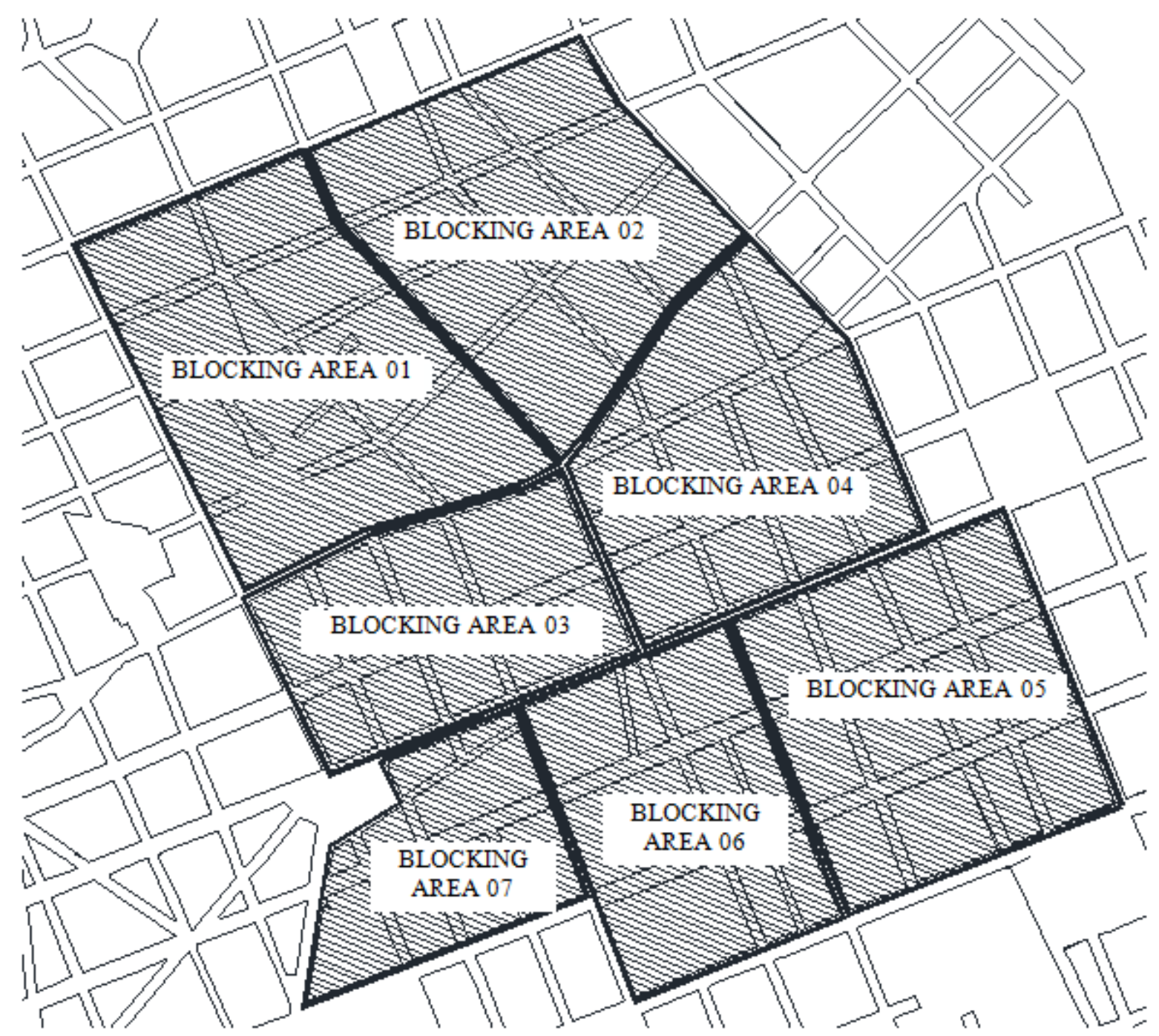

Figure 4. Urban area divided into blocking areas.

- maximum $6 \times 6$ city block groups;

- dimensioned for supplying up to 1,000 autonomous home units (UDAs);

- maximum total extension of 8,000 meters for pipeline networks, located along sidewalks;

- blocking areas supplied by low pressure pipe rings - side pipe network at $4.0 \mathrm{kgf} / \mathrm{cm}^{2}$;

- a connection of blocking areas with the remainder mesh $\left(4.0 \mathrm{kgf} / \mathrm{cm}^{2}\right.$ side pipeline) always through two block valves. These devices allow the system operator to isolate each blocking area from the remainder system;

- a block valve must exist for each individual customer to be served, positioned in an area which allows easy access when necessary.

As an example, Figure 4 illustrates an urban area divided into seven blocking areas.

\subsection{Mesh Modulation HDPE valve chambers}

In each blocking area built, there is a considerable number of commercial and residential customers connected. For each one, it is necessary to install one block valve, through which is possible to stop supply in case of an eventual accident, maintenance or even a service suspension due to nonpayment.

The HDPE valves used in this case study, with 32 $\mathrm{mm}$ nominal diameter, need to be installed to facilitate the access in operational or emergency situations, being normally accommodated in concrete underground chambers, located along the network path (in sidewalks) with specific manholes, as illustrated in Figure 5. 


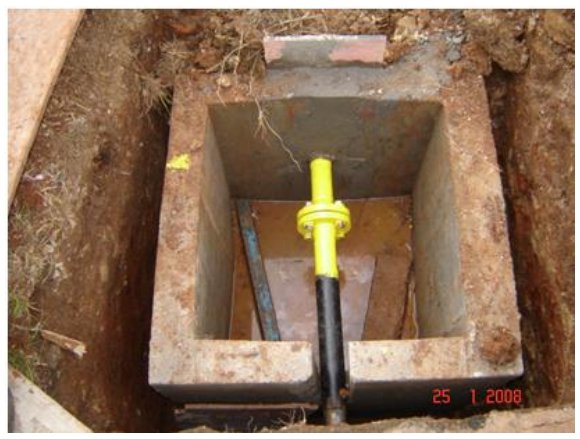

Figure 5. Image of a concrete valve chamber of a customer service branch.
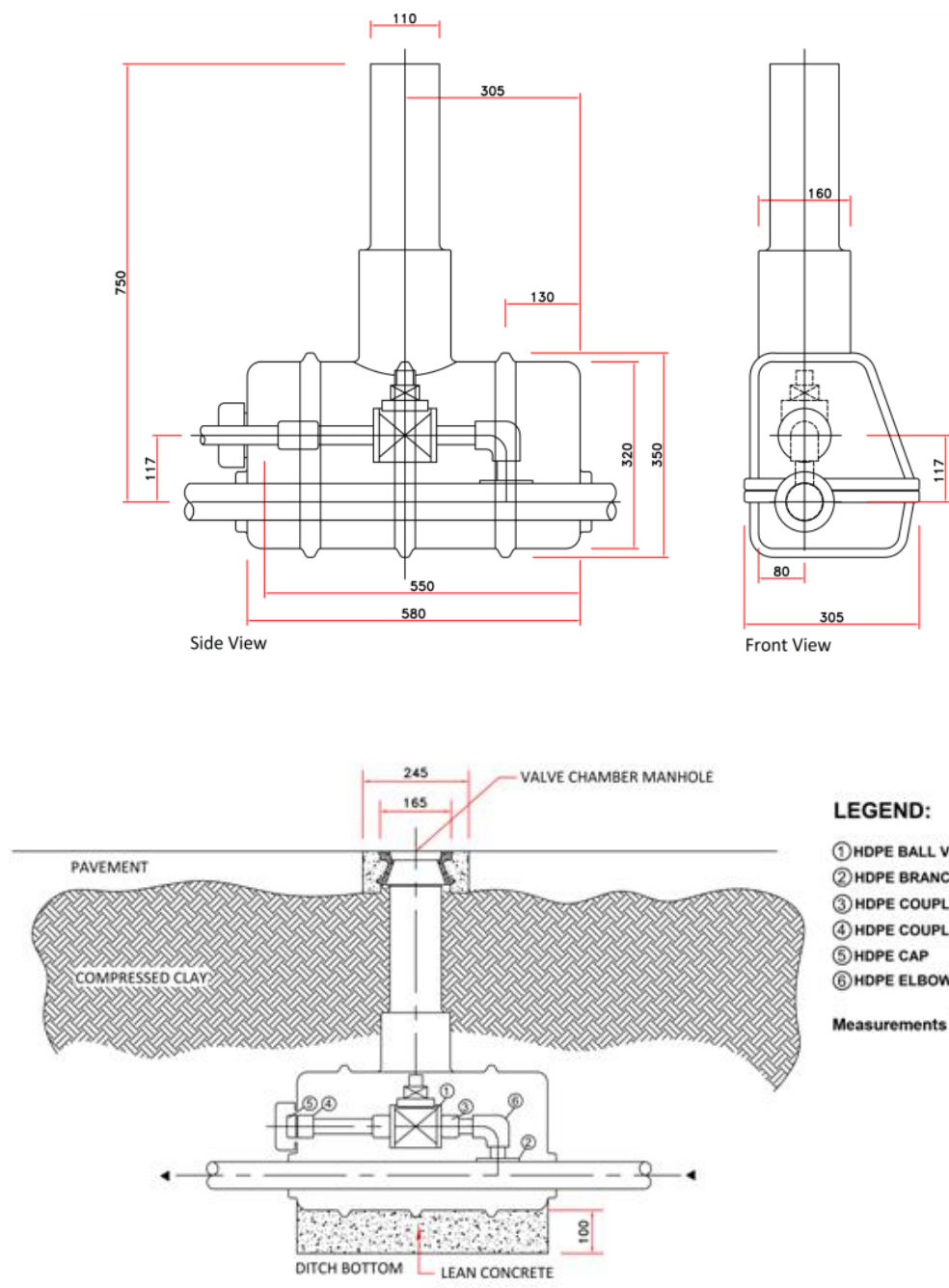

LEGEND:

(1) Hope balL VAlve

(2) HDPE BRANCH SADDLE

(3) HDPE COUPLER

(4) HDPE COUPLER

(5) HDPE CAP

(6) HDPE ELBOW $90^{\circ}$

Measurements in mm

Figure 6. HDPE valve chamber developed in substitution of concrete made chambers in customer service branches.

However, at some point, urban sidewalks gather large number of underground utilities, such as water, sewage, draining, electricity, and telecom. Based on this spacial limitation, COMPAGAS identified the need for development of alternatives aiming to optimize dimensions and construction features of these specific devices. In this context, after studying the case, the authors of this paper identified using plastic chambers made of HDPE as a viable solution to the problem, making a specific injection mould for them. Figure 6 illustrates a technical drawing detail extracted from the original 


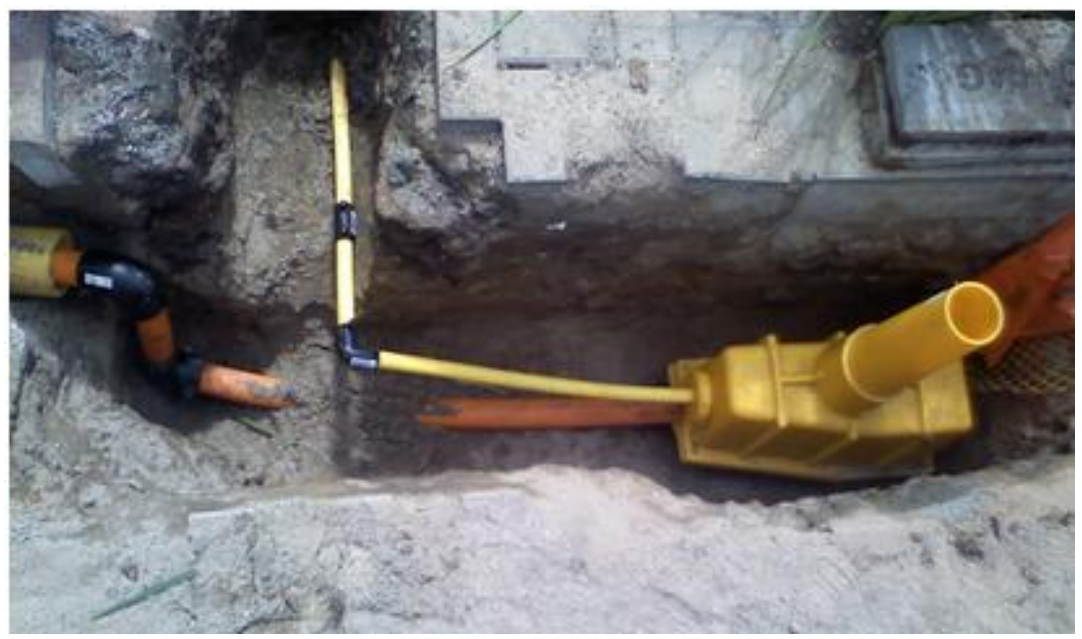

Figure 7. HDPE valve chamber assembly in site.

proposition. The illustration shows a bipartite assembly process, which allows flexibility for its installation in site.

Furthermore, the referred chamber has a vertical access tube covered by a manhole, installed at the sidewalk level, through which the valve can be accessed and also operated with the use of a specific tool. In this case study, the HDPE pipelines considered were installed along sidewalks under a 60 centimeter average covering depth, considering the pipe superior generatrix.

In the sequence, Figure 7 illustrates the referred chamber assembly during the construction of certain customer service branch.

\section{RESULTS}

\subsection{Case study}

This case study presents the natural gas distribution system implemented in the city of Curitiba, the capital of Paraná. The guidelines followed by the present study are described in previous sections.

The natural gas urban distribution system in Curitiba uses executive designs for residential and commercial service pipelines. The system has about 315 kilometers of total extension, of which about 125 kilometers are already built, serving about 18,000 customers. Its implementation started in 2004, following partial extensions according to demand. It takes place inside a single blocking area, always between a new customer address, or even a new blocking area set, and the closest existing network.

The pipelines were dimensioned through the general flow equation using the SynerGEE software. To determine local consumption parameters, market qualitative researches and obtained data analysis were done. Pipe-sizing flow was correlated to the default consumption per linear meter criteria.

- The results of dimensioning obtained through those parameters were:

- carbon steel pipes with 8 or 6 inch nominal diameters or, alternatively, PE-100 polyethylene pipes with 160 or $200 \mathrm{~mm}$ outer diameter, for side pipelines at $7 \mathrm{kgf} / \mathrm{cm}^{2}$;

- PE-80 polyethylene pipes with $160 \mathrm{~mm}$ outer diameter, for side pipelines at $4 \mathrm{kgf} / \mathrm{cm}^{2}$;

- PE-80 polyethylene pipes with $63 \mathrm{~mm}$ outer diameter, for blocking areas at $4 \mathrm{kgf} / \mathrm{cm}^{2}$;

- PE-80 polyethylene pipes with 32 millimeter outer diameter, for service branches.

These pipes were dimensioned considering the use of commercial diameters and a step- system implementation. The goal was to ease operations and rationalize investments. The on-demand construction allows payback to start right after its conclusion, and customer consumption is expected to grow in same pace of investment. 


\section{CONCLUSIONS}

Establishing design guidelines for natural gas urban pipeline networks has a significant impact on project viability, as well as on system operational and maintenance conditions. The eventual change in guideline criteria may impact implementation costs. A model focused on constructive and operational flexibility can absorb eventual variations, ensuring a faster payback and a better return on investment. Such model would allow a partial execution with immediate customer supplyand bringing a relative income. A well done data collection and a good methodology for its analysis are of extreme significance in this context.

Finally, the suggestion of using HDPE valve chambers, in substitution of traditional concrete chambers, granted COMPAGAS about 30\% direct cost reduction considering the set of components and services for these devices. It also reduced installation time and lowered indirect costs. For these reasons, since its initial conception, plastic chambers have been used massively by the company.

\section{REFERENCES}

ABNT, NBR 12.712 - Projeto de Sistemas de Transmissão e Distribuição de Gás Combustível. Rio de Janeiro-RJ, 2002. (in portuguese).
ABNT, NBR 14.461 - Sistemas para Distribuição de Gás Combustível para rede enterradas - Tubos e Conexões de Polietileno PE80 e PE100 - Instalação em obra por Método Destrutivo (vala a céu aberto). Rio de Janeiro-RJ, 2000. (in portuguese).

ASME, ASME B31.8 - Gas Transmission and Distribution Piping Systems. Houston- TX, 2007.

ABEGAS - ASSOCIAÇÃO BRASILEIRA DAS EMPRESAS DE GÁS. Relatório ABEGAS Mercado e Distribuição 2012, Ano VI - no 52. Accessed on 15 October 2014 (in Portuguese).

Belloir P., Libert D., New Routes to High Processing Polyethylene Pipe Grades - Is the Way to PE125. In: Plastic Pipes XV Conference, 2010, Vancouver, Proceeding PPXV, 1 CD-ROM.

Dheur L., Chai C., Reigneir M., Popa A, Next Frontier in PE100 Product Design: A StructureProperties Approach. In: Plastic Pipes XV Conference, 2010, Vancouver, Proceeding PPXV, 1 CD-ROM.

Frank A., Pinter G., Lang R. W., Fracture Mechanics Lifetime Prediction of PE 80 an PE 100 Pipes under Complex Loading Conditions. In: Plastic Pipes XV Conference, 2010, Vancouver, Proceeding PPXV, 1 CD-ROM. 